\title{
Clinical Study on Congenital Malformations At Birth in A Tertiary Level Hospital in North-East India
}

\author{
Pushpal Chowdhury ${ }^{1}$, R K Praneshwari Devi ${ }^{2}$, Laishram Birendro Singh ${ }^{3}$, \\ Apurva Shriram Thakare ${ }^{4}$, Zigmee Dorjee Tamang ${ }^{5}$, Satadip Debroy ${ }^{6}$, \\ Tseten Zangmu Bhutia ${ }^{7}$, Puja Banik ${ }^{8}$ \\ 145678(Post Graduate Trainee, Department of Obstetrics and Gynaecology, Regional Institute of Medical \\ Sciences, Imphal, Manipur, India) \\ 2(Associate Professor, Department of Obstetrics and Gynaecology, Regional Institute of Medical Sciences, \\ Imphal, Manipur, India) \\ 3(Assistant Professor, Department of Orthopaedics, Jawaharlal Nehru Institute of Medical Sciences, Imphal, \\ Manipur, India)
}

\begin{abstract}
This was a clinical descriptive study of congenital malformations in new born in a tertiary level hospital in north-east India from the period $1^{\text {st }}$ January 2015 to $30^{\text {th }}$ April, 2016. Out of 14912 births, 159 had congenital malformation making an incidence of $1.06 \%$. The incidence was more in males, in preterm babies, and more in stillborn. Oligohydramnios was associated with the highest risk of congenital malformation. The most common congenital malformation was cleft lip followed by CTEV.
\end{abstract}

Keywords: Birth, Congenital, Incidence, Malformation, Stillborn

\section{Introduction}

Congenital malformation represents defects in morphogenesis during early foetal life. According to the World Health Organization (WHO) document of 1972, the term congenital malformations should be confined to structural defects at birth. The leading causes of infant morbidity and mortality in poorer countries are malnutrition and infections, whereas in developed countries they are cancer, accidents and congenital malformations. Congenital anomalies account for $8-15 \%$ of perinatal deaths and $13-16 \%$ of neonatal deaths in India. ${ }^{1}$ Prevalence studies are important to establish baseline rates, to document the changes that take place over the period of time, and to find out the aetiology. Different registration systems of infants, international organisations, worldwide monitoring and surveillance have been established to enumerate the possible causes and prediction of occurences of congenital malformations and to establish prevention strategies. ${ }^{2}$ Congenital malformation will begin to emerge as one of the major childhood health problems. Treatment and rehabilitation of children with congenital malformations is costly and complete recovery is usually impossible. Approximately, $66 \%$ of major malformations have no recognized aetiology and most of them have multifactorial inheritance. These defects can occur for many reasons including inherited genetic conditions, poor diet, toxic exposure of the foetus for example, to alcohol, birth injury and, in many other cases, for unknown reasons. In the present study, we try to determine the overall incidence, types and distribution of various congenital anomalies both in live born and still born foetuses, and also to find out the major associated maternal and foetal associated risk factors.

\section{Materials And Methods}

This was a descriptive, cross sectional study of newborns and stillborn babies delivered at Regional Institute of Medical Sciences, Imphal, from the period $1^{\text {st }}$ January 2015 to $30^{\text {th }}$ April, 2016. Data collection was done in the form of structured form which contained details about variable like date of admission, age, history of chronic illness, drug ingestion, exposure to X-ray, history of consanguineous marriage in other offspring, etc. and that of the baby like live or still birth, gestational age, birth order, existence of congenital anomaly and the type of it. No autopsy examinations were performed. There were a total of 14789 live births and 123 still births during this period. The study material comprised 14912 births (both live and still) and their 14773 mothers(139twin deliveries). Congenital malformations were divided into central nervous system (CNS), musculoskeletal, gastrointestinal, genitourinary, cardiovascular (CVS), syndromes, and miscellaneous disorders.

\section{Results}

Out of the total 14912 babies delivered, 14789 were live births and 123 were stillbirths. The number of babies with congenital malformations diagnosed at birth or within the first week of life was 159(1.06\%).TABLE 1 gives the frequency and sex distribution of congenital malformations. Out of the 14634 singleton births, 157 
$(1.07 \%)$ were malformed, whereas 2 of the 139 pairs of twins had birth defects. The sex-wise distribution was $56 \%$ males and $44 \%$ females, giving an M:F ratio of 1.28:1, and there were three cases of ambiguous genitalia. Congenital malformations were seen more in stillbirths as compared to live births, the frequency being $6.50 \%$ and $1 . .02 \%$, respectively. Eight of the 159 malformed babies $(5.03 \%)$ were still born. TABLE 2 shows the frequency of congenital malformations in relation to foetal and maternal factors. Women less than 20 years had $3.11 \%$ babies with congenital anomalies, and the mothers of babies with congenital anomalies were mostly between 20 and 30 years, i.e. $66 \%$, and $31 \%$ of the mothers were above 30 years.

Table 1

\begin{tabular}{|c|c|c|c|}
\hline & Total Cases & Malformed Babies & Percentage \\
\hline Total Births & 14912 & 159 & 1.06 \\
\hline Still Births & 123 & 8 & 6.50 \\
\hline Live Births & 14789 & 151 & 1.02 \\
\hline Male & 8325 & 98 & 0.85 \\
\hline Female & 6584 & 53 & 1.24 \\
\hline Ambiguous & 3 & 0 & \\
\hline
\end{tabular}

Table 2

\begin{tabular}{|c|c|c|c|}
\hline & \multicolumn{2}{|c|}{ FOETAL FACTORS } & \multirow[t]{2}{*}{ PERCENTAGE } \\
\hline $\begin{array}{c}\text { BIRTH } \\
\text { WEIGHT(GRAMS) }\end{array}$ & TOTAL CASES & $\begin{array}{l}\text { MALFORMED } \\
\text { PATIENTS }\end{array}$ & \\
\hline$<1000$ & 37 & 32 & 20.12 \\
\hline $1000-15000$ & 205 & 34 & 21.38 \\
\hline $1501-2000$ & 254 & 35 & 22.01 \\
\hline $2001-2500$ & 356 & 19 & 11.94 \\
\hline$>2500$ & 14060 & 39 & 24.52 \\
\hline \multicolumn{4}{|c|}{ GESTATIONAL AGE } \\
\hline PRETERM & 3897 & 97 & 61.00 \\
\hline TERM & 10420 & 59 & 37.10 \\
\hline POSTTERM & 456 & 3 & 1.88 \\
\hline \multicolumn{4}{|c|}{ MATERNAL FACTOR } \\
\hline \multicolumn{4}{|c|}{ MATERNAL AGE (YEARS) } \\
\hline$<20$ & 289 & 9 & 5.66 \\
\hline $21-25$ & 2098 & 44 & 27.67 \\
\hline $26-30$ & 7708 & 67 & 42.13 \\
\hline$>30$ & 4678 & 37 & 23.27 \\
\hline \multicolumn{4}{|c|}{ PARITY } \\
\hline PRIMI & 1089 & 43 & 27 \\
\hline PARA1-3 & 10898 & 90 & 56 \\
\hline $\begin{array}{c}\text { PARA } 4 \text { AND } \\
\text { MORE }\end{array}$ & 2786 & 26 & 17 \\
\hline \multicolumn{4}{|l|}{$\begin{array}{c}\text { MODE OF } \\
\text { DELIVERY }\end{array}$} \\
\hline LSCS & 4589 & 36 & 77 \\
\hline $\begin{array}{l}\text { VAGINAL } \\
\text { DELIVERY }\end{array}$ & 10184 & 123 & 23 \\
\hline
\end{tabular}

History of parental consanguinity was present in 4 cases of congenital 8 malformations in our study. Babies with congenital anomalies were of the first order (7.30\%), and second order to third order (73.08\%). More than four or fourth birth order was associated with $18.16 \%$ of the anomalies. There was a history of oligohydramnios in 45 cases and polyhydramnios in 23cases. Also, 23/159 mothers (14.47\%) had a history of previous abortions, 6/159 (3.77\%) were diabetic mothers and 5/159 (2.79) had a history of congenital heart disease in previous child or malformed babies. TABLE 3 shows the systemic distribution and the incidence of individual congenital malformations. Gastrointestinal malformations were the most common in live births, followed by musculoskeletal system malformations. The incidence of CNS malformations was higher in the stillborn. 


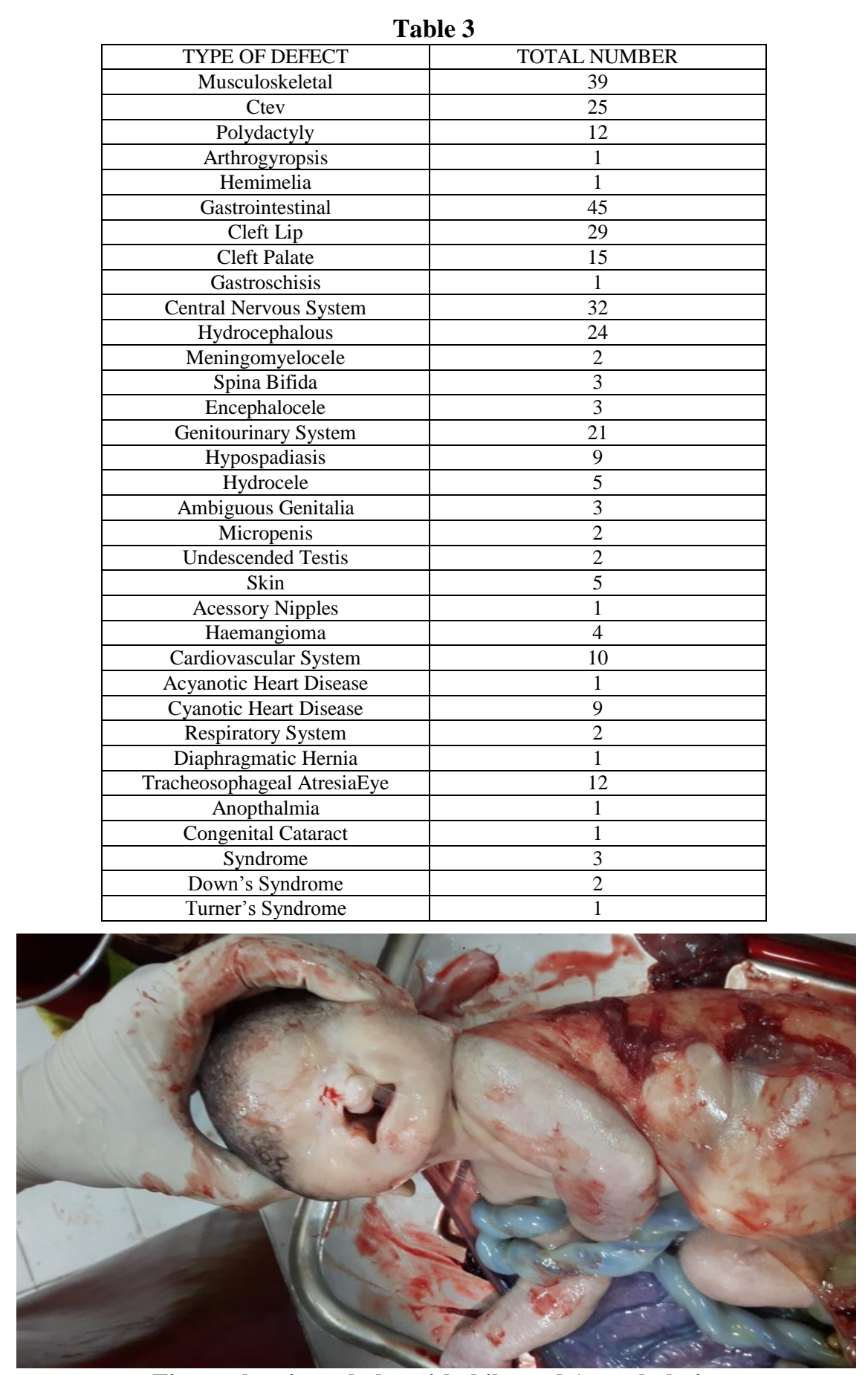

Figure showing a baby with bilateral Anopthalmia

\section{Discussion}

Congenital malformations are an important cause of perinatal mortality and childhood morbidity. The number of birth defects is increasing antenatally and during the neonatal period due to advanced diagnostic technology, especially USG. ${ }^{1}$ The pattern and prevalence of congenital malformations may vary over time or with geographical location, reflecting a complex interaction of known and unknown genetic and environmental factors, including socio-cultural, racial and ethnic factors. ${ }^{4}$

In the present study the incidence of congenital malformation was $1.06 \%$ which is comparable with earlier studies from same part of the country ${ }^{5}$. There are other reports from different parts of the world representing different frequency of congenital malformations ${ }^{2}$. Although we got nearly the same result as reported in other studies, the prevalence of congenital anomaly have been more than the present rate, if it was a community based study and not merely in a tertiary care setup. 
With regard to the pattern of congenital anomalies in the study, the most common system involved was GIT (gastrointestinal system) $(28.30 \%)$, followed by musculoskeletal $(24.53 \%)$, CNS(central nervous system)(20.13\%), Genitourinary system(13.21\%), CVS(Cardiovascular System)(6.29\%), Skin(3.14\%), Eye(1.26\%), Respiratory System(1.26\%), syndromes(1.26\%). The prevalence of cardiovascular malformations was found to be low in this study. The results conform to studies conducted in same part of the country ${ }^{5}$. Some studies from other parts of the country have reported higher prevalence of CVS malformations ${ }^{1}$, musculoskeletal malformations ${ }^{6,5}$ where as some studies have reported higher prevalence of CNS malformations ${ }^{2,7}$.

More male babies were born with congenital malformations than females which is consistent with other studies $^{1,4}$. It may be because of the fact that the females were afflicted with more lethal congenital malformations and could not survive to be born with signs of life.

Taksande et al ${ }^{1,}$ Parmar et $\mathrm{al}^{3}$, Baruah et $\mathrm{al}^{5}$ found increased prevalence of congenital malformations in preterm babies. In this study also, the prevalence of congenital malformations were much higher in preterm babies $(61 \%)$. Sarkar et $\mathrm{al}^{4}$ reported a higher prevalence of congenital malformations in low birth weight babies which is in accordance with our study $(75 \%)$. In this study the highest prevalence of congenital malformations was found in the maternal age group of (26-30) years. Taksande et $\mathrm{al}^{1}$, Datta et $\mathrm{al}^{9}$ found increased prevalence of congenital malformations in maternal age group of 35 years or more, where as Sarkar et $\mathrm{al}^{4}$ higher congenital malformations in the maternal age group of 25-29 years which is in accordance with our study.

Previous studies ${ }^{1,4}$ have demonstrated increased incidence of congenital malformations with increasing birth order, but in this study the highest prevalence of congenital malformations were found in the parity 1 to parity3.

This study found increased prevalence of congenital malformations in the babies that were delivered vaginally which is in accordance with other studies ${ }^{3}$. History of consanguineous marriage was found in 4 cases in this study where as some studies have reported increased incidence of malformations in consanguineous marriages (double risk) ${ }^{8}$.

\section{Conclusion}

Congenital malformations are a major cause of still births and infant mortality which must be identified and surgical correction attempted, if possible. There should be widespread education in the community regarding the common congenital malformations, their outcomes and possible available modes of treatment.

\section{References}

[1]. Taksande A,Vihekar K,Chaturvedi P,Jain M.Congenital malformations at birth in Central India: A rural medical college hospital based study.Indian J Hum Genet.2010;16(3);159-163.

[2]. Abdolahi MH,Maher KHM,Afsharnia F,Dastgiri S.Prevalence of Congenital Anomalies:A Community-Based Study in the Northwest of Iran.ISRN Pediatrics.2014;1-5.

[3]. Parmar A,Rathod PS,Patel VS,Patel MS.A Study of congenital Anomalies In Newborn.NJIRM.2010;1(1):13-17.

[4]. Sarkar S,Patra C,Dasgupta KM,Nayek K,Karmakar RP.Prevalence of Congenital Anomalies in Neonates and Associated Risk Factors in A tertiary Care Hospital in Eastern India.Journal of Clinical Nenatology.2013;2(3):131-137.

[5]. Baruah J,Kusre G,Bora R.Pattern of Gross Congenital Malformations in a tertiary Hospital in Northeast India.Indian J Pediatr.2015;82(10):917-22.

[6]. Bhat BV,Babu L.Congenital malformations at birth—a prospective study from south India.1998;65(6):873-81.

[7]. Grover N.Congenital malformations in Shimla.Indian J Pediatr.2000;67(4)249-51.

[8]. Sheridan E,Wright J,Small N,Corry CP,Oddie S, Whibley C et al.Risk factors for congenital anomaly in a multiethnic birth cohort:an analysis of the born in Bradforn study.2013;382(9901):1350-9.

[9]. Datta V,Chaturvedi P.Congenital malformations in rural Maharashtra. Indian Pediatr.2000;37:998-1001. 